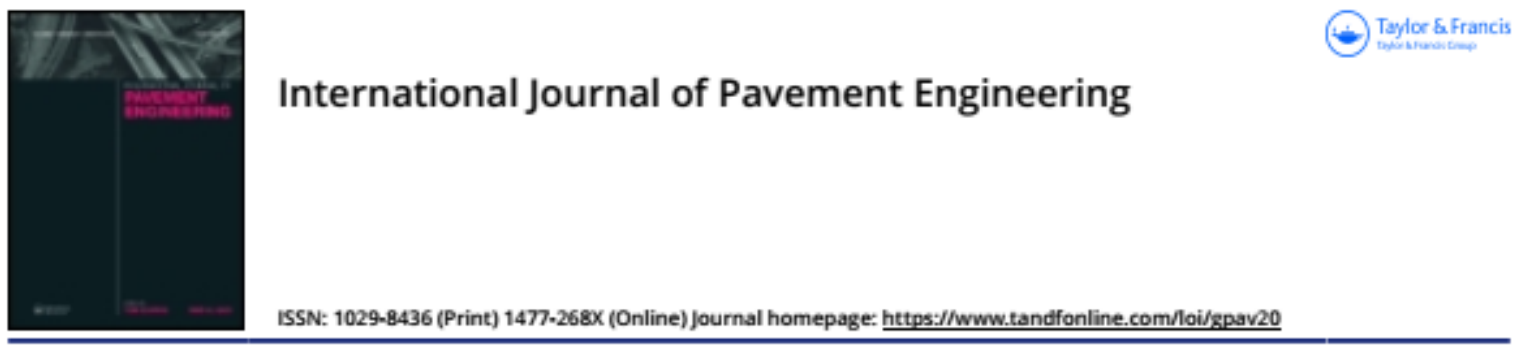

\title{
Moisture susceptibility of hydrated lime modified mastics using adhesion test methods and surface free energy techniques
}

Syed Bilal Ahmed Zaidi, Gordon D. Airey, James Grenfell, Rami M. Alfaqawi, Imtiaz Ahmed, Naveed Ahmad \& Mike Haynes

To cite this article: Syed Bilal Ahmed Zaidi, Gordon D. Airey, James Grenfell, Rami M. Alfaqawi, Imtiaz Ahmed, Naveed Ahmad \& Mike Haynes (2019): Moisture susceptibility of hydrated lime modified mastics using adhesion test methods and surface free energy techniques, International Journal of Pavement Engineering

To link to this article: https://doi.org/10.1080/10298436.2019.1648811

曲 Published online: 05 Aug 2019.

Submit your article to this journal $\square$

(1) View Crossmark data 5

Full Terms \& Conditions of access and use can be found at https://www.tandfonline.com/action/journallnformation?journalCode-gpav20 


\title{
Moisture Susceptibility of Hydrated Lime Modified Mastics Using Adhesion Test Methods and Surface Free Energy Techniques
}

\begin{abstract}
Moisture damage is one of the major factors that has been reported to affect the performance of asphalt pavements with asphalt mixture performance depending mainly on the bond strength between bitumen, aggregate and mineral filler. In the presence of moisture, this bond weakens and results in premature pavement failure due to cohesion or adhesion loss. One of the many ways of mitigating moisture damage effects is the use of anti-stripping agents like liquid polymers, Portland cement, hydrated lime, fly ash, flue dust, etc. Hydrated lime has been found to be one of the most efficient anti-stripping agents among the common additives used with asphalt mixtures. This study attempts to quantify the bond strength of hydrated lime modified mastics with different aggregates under moisture conditions using a combination of surface free energy techniques and conventional adhesion test methods. From the surface free energy (SFE) technique, the moisture susceptibility was studied in the form of dry work of adhesion, work of debonding and various energy parameters. Two conventional techniques, the PATTI test and the rolling bottle test were used to assess bond strength under wet conditions. The results of all three techniques lead to the same conclusion that there was a positive effect of HL addition observed in case of granite aggregates with the best performance being found in the mastic having $20 \% \mathrm{HL}$ (equivalent to $2 \% \mathrm{HL}$ in the total asphalt mixture). On the other hand, the mastic containing HL when used with limestone aggregates did not show any improvement of the adhesion properties under moisture conditions. It can be concluded that hydrated lime is an active filler that improves moisture damage resistance compared to the other natural fillers but that the improvement is highly dependent on aggregate minerology.
\end{abstract}

Keywords: moisture damage, hydrated lime, surface energy, adhesion, rolling bottle test 


\section{Introduction}

Asphalt mixtures are liable to suffer a decrease in strength and stiffness as a result of moisture damage (Masad et al 2006; Grenfell et al 2012). This damage is caused by two main mechanisms, firstly, loss of adhesion between aggregates and bitumen called stripping and, secondly, loss of cohesion within the bitumen (or bitumen-filler mastic) known as softening when the material is subjected to moisture (Airey et al 2008; Little and Bhasin 2006). Although early road failure may not be directly attributed to moisture damage, it may indirectly affect the performance of the pavement by increasing the severity of already existing distresses such as potholes, cracking, rutting and ravelling (Miller and Bellinger 2003).

One of the most popular, useful and cost-effective ways used by transportation agencies to mitigate moisture damage is through the use of various additives and modifiers. Hydrated lime is one such product that has been successfully used as an additive in asphalt mixtures and gained widespread usage in the 1970s in the USA due to a drop in the quality of bitumen associated with the petroleum crisis (Kandhal and Rickards 2001). Due to its enhanced performance against distresses from moisture damage and frost, hydrated lime is now estimated to be used in about $10 \%$ of the asphalt mixtures produced in the USA (Hicks and Scholz 2003). Although the majority of research on the use of HL in asphalt mixtures has been carried out in the USA, the beneficial effects of HL have been reported worldwide, especially in Europe (Lesueur et al 2013). In UK, the routine use of HL to enhance the performance of asphalt mixtures only began in the early 2000s and research into the relative performance of HL with various aggregate types is still urgently required.

In most of the previous studies describing the beneficial effect of HL against moisture damage, moisture sensitivity is simply related to the mechanical properties of the bulk asphalt mixture (Airey et al. 2008; Kim et al. 2008; Maldonaldo 2008; Mohammad et al. 2008; Sebaaly et al. 2006) without mentioning the effect of physical and/or chemical changes on aggregate or binder with the addition of hydrated lime. These physico-chemical properties are directly related to the adhesive characteristics of the two materials and are responsible for adhesion or debonding between the materials (Manual Series No. 24, 2007). Surface energy properties of the materials can be used to assess these adhesive characteristics (Bhasin 2007) and are considered to truly represent the physico-chemical surface characteristics of bitumen and 
aggregates and have been successfully used as a tool for the selection of moisture-resistant materials (Cheng et al. 2002a).

This paper describes an investigation of the moisture damage behaviour of HL modified mastics combined with commonly used aggregates in the UK under moisture susceptible conditions. Two aggregates sources from the UK were selected along with a standard 40/60 penetration grade bitumen. The study attempts to quantify the bond strength of hydrated lime modified mastics with two aggregates under moisture conditions using a combination of surface free energy (SFE) techniques and conventional adhesion test methods. Although there are some studies quantifying the effect of hydrated lime on moisture susceptibility of asphalt mixture using surface energy techniques (Manual Series No. 24, 2007; Nejad et al. 2013), their scope is very limited. Due to the complex nature of asphalt materials and the fact that the surface energy properties of the material (bitumen and aggregate) can be considerably different to its bulk chemistry, the use of SFE and related theories to address moisture damage is not straight forward (Kim, 2009). A complete characterization is only possible once results from SFE measurements and calculations are compared with those of conventional adhesion tests available for moisture susceptibility analysis.

Tests like the rolling bottle test (RBT) and Pneumatic Adhesion Tensile Testing Instrument (PATTI) test are considered good for moisture susceptibility analysis of aggregate-bitumen combinations (Airey \& Choi, 2006; Zhang et al, 2017). The RBT and PATTI techniques have, therefore, been included to provide a comparison to the surface energy results for various bitumen-aggregate combinations. All three approaches have a strong relation with each other as bond strength properties can be assessed, either directly or indirectly, using each technique under a moisture susceptible environment. For the surface energy technique, bond strength can be assessed using work of adhesion under dry and wet conditions (Bhasin et al 2006). In the PATTI test, bond strength can be studied in terms of pull-off tensile strength under dry and wet conditions (Santagata et al 2009; Zhang et al 2015) and in the rolling bottle test bond strength between a binder and aggregate combination can be evaluated by recording retained bitumen coating on aggregate surfaces after the influence of mechanical stirring in water (Liu et al 2014). This paper presents results for all three techniques on the same binder, mastic and aggregate combinations to evaluate the sensitivity of the different techniques and to establish, firstly, whether a relation exists between them and, secondly, the nature of this relation. 


\section{Materials}

Two aggregate sources, granite and limestone, were selected for this research study. To get an idea about the mineralogy of the different aggregates, the results from a mineral liberation analyser (MLA) are presented in Table 1 for the two aggregate types and a sample picture of the MLA scan for limestone aggregates is presented in Figure 1. The MLA is an automated mineral analysis system that can identify minerals in polished sections of drill cores, particulate or lump materials and quantify a wide range of mineral characteristics, such as mineral abundance, grain size and liberation. The results shown in

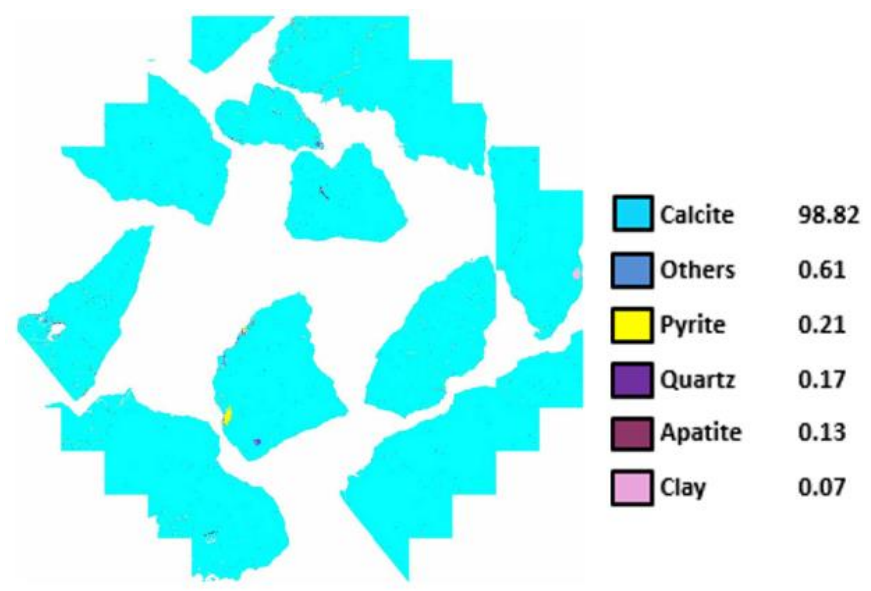

Figure 1 were obtained using an FEI Quanta 600 SEM with MLA capability to determine the mineral phases of the two aggregates (Grenfell et al 2014; Zhang et al 2015). Aggregate samples were prepared by casting aggregates in resin, followed by polishing of the surface. The samples were then carbon coated to make them electron conductive and scanned in BSE mode with the Electron Dispersive X-ray analysis (EDX) being carried out in an array of spots across the particles. The resultant spectra were then used to determine mineral phases at specific points in the microstructure which allowed mineralogical maps to be generated for each of the two aggregate types.

As filler type significantly affects asphalt mixture properties, three fillers were selected consisting of limestone, granite and hydrated lime (HL). Some of the important filler properties are presented in Table 2. The amount of mineral filler blended in the bitumen was kept at 50\% by mass (Faheem et al. 2011; Wang et al. 2011). Each aggregate type was tested with four combinations of binders including one neat 40/60 pen bitumen (40/60 Neat) and three mastics. A total of six different types of mastics were used in combination with the two types of aggregate. The notation, composition and the type of the aggregate used with these mastics are 
presented in Table 3. As this study focused on the effect of HL on the performance of asphalt mixtures, the other two fillers i.e. limestone and granite were used with their parent aggregate type and HL was used as a replacement for certain percentages within the mastic.

For mastic preparation, a small amount of bitumen (about 300 grams) was heated at $160^{\circ} \mathrm{C}$ in the oven in a small container. In another container, the required amount of filler (either one type or combination of two) was prepared. The tin containing the bitumen was then placed on a hot plate maintained at $160^{\circ} \mathrm{C}$, the bitumen was stirred by hand and the accurate mass of filler was added slowly while the stirring was continued until the mastic became homogenous (mixing takes approximately 5-10 minutes). The mastic was continuously stirred as it was cooling down until the temperature became low enough to prevent the filler from settling. The mastics were then stored for later testing. Before each test, the mastics were heated to a liquid and stirred to ensure homogeneity. For each mastic set, in order to guarantee that the fillers were homogeneously distributed within the mastics, samples were taken from different parts of the mastic after each mixing process and tested for softening point to ensure their consistency and comparison to each other. The results show that hand mixing was reliable and repeatable and the fillers were homogeneously distributed within the mastic.

Mastic with different filler combinations showed different stiffening effect which was evaluated through viscosity and softening point tests. The mastic having more HL was observed to be stiffer compared to the one having less or no hydrated lime. The obvious reason for this increased stiffness was the higher Rigden voids in hydrated lime compared to other fillers as presented in Table 2.

\section{Test Methods}

\subsection{Surface Free Energy}

Surface free energy (SFE) is defined as the amount of energy/work required to create a unit surface area of a material in a vacuum (Good 1966; van Oss et al 1988). Thermodynamic theory (also known as adsorption theory) can be used to relate SFE of different substrates (liquids and solids) to their adhesive and cohesive properties (Schultz and Nadrin 1994). Using values of SFE of bitumen and aggregates, adhesive bond parameters, with and without the presence of 
water, can be calculated for different bitumen, aggregate and filler combinations (Cheng et al. 2002).

\subsubsection{SFE measurements for bitumen}

The SFE of a liquid or solid cannot be measured directly and therefore indirect methods are used to calculate the SFE for both liquid and solids using various measurement techniques and the known SFE values of different solvents. The SFEs of the bitumen and mastics used in this study were calculated by means of a Cahn model Dynamic Contact Analyzer (DCA) apparatus using the Wilhelmy Plate method (Adamson and Gast 1997; Little and Bhasin 2007; Grenfell et al 2014). The surface energy of the binder and mastics were calculated using the contact angles that a set of three probe liquids make with the binder under dynamic conditions (Little and Bhasin 2006; Grenfell et al 2014). The three probe liquids which were used in this study are water, glycerol and diiodomethane. These probe liquids have been selected on the basis of guidelines given by Bhasin (2007) which states that surface energy values for probe liquids should be greater than that of the solid for contact angle measurements. Using a solvent with low surface energy/surface tension will cause the solvent to readily spread on the substrate and it would be difficult to get an accurate angle measurement. Also, the substrate should be tested with a combination of at least one non-polar and two polar liquids. Out of the two polar probes, one should be acidic and the other should be basic, or they may have a combination of acidbase character. This is required to fully characterize the surface properties of the substrate and to remove errors that may occur if liquids with very similar surface energy properties are used. The SFE components of the probe liquids used for the binder are presented in Table 4.

A detailed procedure to measure surface energy using the DCA has been presented by (Bhasin (2007)) and Grenfell et al (2014). In the DCA test, a thin glass plate (40mm x 24mm x $0.45 \mathrm{~mm})$ coated with binder is immersed ( $5 \mathrm{~mm}$ depth) and withdrawn from a probe liquid at a constant speed of $40 \mu \mathrm{m} / \mathrm{s}$ while continuously recording the change in the mass of binder coated glass plate against the depth of immersion (Adamson and Gast 1997). These results are then used to calculate the angle between the binder and at least one probe liquid. All tests were performed at a room temperature of $23 \pm 2{ }^{\circ} \mathrm{C}$ and relative humidity of $50 \pm 5 \%$. Three replicates for each binder and probe liquid combination were performed. 
Contact angle results from the three probe liquids were used in equation 1 to give three simultaneous equations which upon solving give three components $\left(\gamma^{L W}, \gamma^{+}\right.$and $\left.\gamma^{-}\right)$of surface energy. These estimated components of surface energy are then used to calculate total surface energy of binders $\left(\gamma_{B}^{T}\right)$ with the help of equation 2 .

$$
\begin{gathered}
W_{B L i}=\gamma_{L i}(1+\cos \theta)=2 \sqrt{\gamma_{B}^{L W} \gamma_{L i}^{L W}}+2 \sqrt{\gamma_{B}^{-} \gamma_{L i}^{+}}+2 \sqrt{\gamma_{B}^{+} \gamma_{L i}^{-}} \\
\gamma_{B}^{T}=\gamma_{B}^{L W}+\sqrt[2]{\gamma_{B}^{-} \gamma_{B}^{+}}
\end{gathered}
$$

Where, $W_{B L i}$ is the work of adhesion between binder and probe liquid, $\gamma_{L i}$ is the total surface energy of probe liquid and $\theta$ represents the contact angle between binder and probe liquid.

\subsubsection{SFE measurements for aggregates}

The surface energy components of material with high energy surfaces, such as aggregates, can be calculated with vapour sorption techniques such as the universal sorption or dynamic vapour sorption techniques (Bhasin and Little 2007; Grenfell et al 2014). These techniques use the gas adsorption characteristics of the selected solvents with known surface energy to measure the surface free energy of aggregates indirectly. This method is used universally for aggregates having different size, shape, mineralogy and surface texture.

Oven dried aggregates passing the 5-mm sieve and retained on the 2.36-mm sieve were used along with four probe liquids; octane, chloroform, ethyl acetate and distilled water. Table 5 tabulates the total surface energy of the probe liquids and their components. The upper limit on aggregate size is dictated by the material holding capacity of the sample chamber. The cleaned oven-dried aggregate samples (less than $10 \mathrm{~g}$ ) were again pre-heated in the DVS sample chamber at a temperature of $110^{\circ} \mathrm{C}$ for up to $5 \mathrm{~h}$ to completely dry the samples before the sorption test.

To perform the sorption test, carefully selected probe vapours were passed through the aggregate sample, under controlled temperature and partial vapour pressure conditions, with the aid of an inert carrier gas (nitrogen). The probes that were chosen for the aggregate testing had relatively low surface tension values as compared to the ones that are used for testing the bitumen to aid the ability to achieve a uniform adsorption monolayer of the probe vapour on 
the aggregate surface. Due to the surface characteristics of the aggregate, vapour probes get adsorbed on their surfaces which results in an increase in the mass of the aggregate sample that is then measured using a sensitive balance. During the test, the aggregate material was exposed to different concentrations/vapour pressures of the probe liquids and the increase in mass of the aggregates because of adsorption of the probe vapours on the aggregate surface was measured. All the tests were performed at a temperature of $25^{\circ} \mathrm{C}$. The change in mass of an aggregate sample was recorded for each increasing partial vapour pressure value to generate sorption isotherms which were used to estimate specific surface area (SSA) and spreading equilibrium pressures of the aggregates.

The change in mass of aggregate was recorded in the DVS chamber with probe liquid vapours at partial pressures ranging from $0 \%-95 \%$. Changes in mass of each aggregate-probe liquid combination were recorded by an ultra-sensitive balance at 14 different partial pressures until equilibrium was achieved at each partial pressure stage (Grenfell et al 2014). The results of these mass changes were plotted against partial pressure to get a sorption isotherm which was used to estimate the spreading pressure and specific surface area for each probe liquid and aggregate combination. These results were then used to calculate the surface energy components of aggregates using equations 3 and 4.

$$
\begin{gathered}
W_{A L i}=\pi_{e}+2 \gamma_{L i}=2 \sqrt{\gamma_{B}^{L W} \gamma_{L i}^{L W}}+2 \sqrt{\gamma_{B}^{-} \gamma_{L i}^{+}}+2 \sqrt{\gamma_{B}^{+} \gamma_{L i}^{-}} \\
\gamma_{A}^{T}=\gamma_{A}^{L W}+2 \sqrt{\gamma_{A}^{-} \gamma_{A}^{+}}
\end{gathered}
$$

Where, $W_{A L i}$ is the work of adhesion between aggregate and probe liquid, $\gamma_{L i}$ is the total surface energy of the probe liquid and $\pi_{e}$ represents the spreading pressure of the probe liquid on aggregate surface.

\subsubsection{Moisture damage assessment using SFE}

Moisture damage depends on the interaction of surface energy components of aggregate, bitumen and water. The adhesive and cohesive bond strengths of a bitumen aggregate system, both with and without the presence of water at the interface, can be calculated using the surface energy concept. Cohesive bond strength or work of cohesion is estimated as twice the total 
surface energy. The adhesive bond strength in dry conditions is referred to as the work of adhesion between binder and aggregate. The higher the value, the greater will be the bond strength between the two materials. The adhesive bond strength in the presence of water is termed the work of debonding and a smaller value (magnitude) indicates a better moisture damage resistance for a given binder and aggregate combination. Work of adhesion and work of debonding can be calculated using equations 5 and 6 respectively, provided the surface energy components of the binder, aggregate and water are known.

$$
\begin{gathered}
\Delta G_{B A}^{a}=2 \sqrt{\gamma_{B}^{L W} \gamma_{A}^{L W}}+2 \sqrt{\gamma_{B}^{+} \gamma_{A}^{-}}+2 \sqrt{\gamma_{B}^{-} \gamma_{A}^{+}} \\
\Delta G_{B W A}^{a}=2 \gamma_{W}^{L W}+2 \sqrt{\gamma_{B}^{L W} \gamma_{A}^{L W}}-2 \sqrt{\gamma_{B}^{L W} \gamma_{W}^{L W}}-2 \sqrt{\gamma_{A}^{L W} \gamma_{W}^{L W}} \\
+4 \sqrt{\gamma_{W}^{+} \gamma_{W}^{-}}-2 \sqrt{\gamma_{W}^{+}}\left(\sqrt{\gamma_{B}^{-}}+\sqrt{\gamma_{A}^{-}}\right)-2 \sqrt{\gamma_{W}^{-}}\left(\sqrt{\gamma_{B}^{+}}+\sqrt{\gamma_{A}^{+}}\right) \\
+2 \sqrt{\gamma_{B}^{+} \gamma_{A}^{-}}+2 \sqrt{\gamma_{B}^{-} \gamma_{A}^{+}}
\end{gathered}
$$

Where, $\gamma_{W}^{L W}, \gamma_{W}^{+}$and $\gamma_{W}^{-}$are the components of surface energy of water and are given in Table 5. Moisture sensitivity of a binder aggregate combination can also be calculated using four energy ratios as suggested by Bhasin (2007) and determined using equations 7, 8, 9 and 10.

$$
\begin{gathered}
E R_{1}=\left|\frac{\Delta G_{B A}^{a}}{\Delta G_{B W A}^{a}}\right| \\
E R_{2}=\left|\frac{\Delta G_{B A}^{a}-\Delta G_{B B}^{a}}{\Delta G_{B W A}^{a}}\right| \\
E R_{3}=E R_{1} \times S S A \\
E R_{4}=E R_{2} \times S S A
\end{gathered}
$$

Where, $\Delta G_{B B}^{a}$ is the work of cohesion and SSA is the specific surface area of the aggregate as computed from the DVS test. 
$\mathrm{ER}_{1}$ quantifies moisture sensitivity with the help of work of adhesion and work of debonding. On the other hand, $\mathrm{ER}_{2}$ considers wettability and work of debonding for moisture damage assessment for a given binder-aggregate system. $\mathrm{ER}_{3}$ and $\mathrm{ER}_{4}$ consider the micro-texture of the aggregates. Micro-texture of the aggregate can be considered to be directly proportional to the specific surface area (SSA). Grenfell et al. (2014) reported that SSA has a large influence on moisture sensitivity of asphalt mixtures so the energy parameters ER3 and ER4 can be considered as more suitable indices for determining the performance of the different aggregatebitumen combinations.

\subsection{Rolling Bottle Test}

The rolling bottle test (RBT) has been conducted in accordance with BS EN 12697-11 (2012). It is a measure of the affinity between aggregate and bitumen. This affinity is measured by visual inspection in terms of the degree of bitumen coating on loose bitumen coated aggregates after the influence of mechanical stirring in water. Clean and fully dried aggregate particles are coated with an approximately $0.1 \mathrm{~mm}$ thick layer of bitumen. These coated aggregates are then stored at room temperature for 12 to 64 hours before testing. For testing, glass bottles are filled to approximately the shoulder of the bottle with deionised water and the coated aggregates and then a glass stirrer are added to the bottles. The bottles are rotated at a speed of 60 rotations per minute for a total of 72 hours. At the end of the first six hours, the samples are emptied from the glass bottles and placed in a test bowl which is then filled with fresh water and the percentage of bitumen coating on the aggregate particles is recorded visually. Each visual determination of binder coverage is carried out independently by two skilled operators. The average degree of binder coverage is calculated by taking the mean of the two operators' results, rounded to nearest 5\%. After that, the water from the test bowl is discarded and aggregate particles are returned to the bottle and refilled with the original water from the beaker. Once the bottles are sealed with their screw caps, the rolling procedure is continued again. This procedure is repeated three more times at the end of 24, 48 and 72 hours and the degree of bitumen coating is estimated as discussed earlier. In the end, the mean value is taken to get an average bitumen coating on the aggregates.

In a previous study by Liu et al. (2013), five empirical tests on loose mixtures were considered for performance evaluation including the static immersion test, rolling bottle test (RBT), boiling water test (BWT), total water immersion test and an ultrasonic method. Surface free 
energy (SFE) tests on aggregate and bitumen were also performed to confirm the performance with these empirical methods. RBT and BWT were found to be the most sensitive procedures among the five empirical procedures in predicting moisture damage performance. Mixture ranking given by RBT was found to be in agreement with the results of SFE testing. Based on the findings of the previous studies on RBT test, it can be concluded that the RBT is one of the most efficient empirical procedures for moisture damage assessment.

\subsection{PATTI Test}

The PATTI test is used to evaluate the bond between aggregate and bitumen/mastic in terms of fracture or tensile strength. This could be the cohesive bond strength or adhesive strength depending on the type of failure. The equipment was developed by the National Institute of Standards and Technology (NIST) with the PATTI test equipment shown in Figure 2a. The PATTI device is used to measure tensile strength, while the camera is used for the analysis of the failure surface. Figure $2 b$ shows a cross-sectional schematic of the setup of the PATTI with the piston attached to a pull-stub which in turn is attached by means of the bitumen coating to the aggregate substrate (Santagata et al. 2009).

The aggregate substrate is prepared by wet cutting boulders into the required shape and size using a diamond-edged saw cutter. These aggregate substrates are then washed to remove any dirt or dust followed by drying to a constant mass. The aggregate substrates are heated at about $70^{\circ} \mathrm{C}$ for one hour before testing. In parallel, bitumen/mastic samples are heated at $150-180^{\circ} \mathrm{C}$. The liquid bitumen/mastic is then poured onto the surface of the substrate and the preheated stub is placed on top using gentle pressure. With the applied vertical pressure, the excessive bitumen/mastic flows out through the vertical channels of the stub. This leaves a constant thickness of $0.8 \mathrm{~mm}$ bitumen film inside the pull off stub. The sample is allowed to cool for at least four hours and then the excessive bitumen/mastic is trimmed using a heated knife or any other suitable sharp tool. A piston is placed on top of the prepared sample and a reaction plate is screwed on top of the piston. Pressure applied by the PATTI is transmitted to the piston and an airtight seal is formed between the gasket of the piston and the surface of aggregate. A constant rate of pressure is applied through the PATTI using a control valve. Data is recorded by the software in the form of applied tensile pressure against time. 
The maximum pressure which separates the bitumen and aggregate surfaces is recorded by the software and the peak tensile strength is calculated using equation 11, by the in-built PATTI quantum gold software.

$$
T_{p o}=\left(\left(P_{b} \times A_{g}\right)-C\right) / A_{p s}
$$

Where, $T_{p o}=$ Pull-off tensile strength $(\mathrm{kPa}), P_{b}=$ Burst pressure $(\mathrm{kPa}), A_{g}=$ Contact area of gasket with relation plate $\left(\mathrm{m}^{2}\right), C=$ Piston constant $(\mathrm{kN}), A_{p s}=$ Area of pull-stub $\left(\mathrm{m}^{2}\right)$

\section{Results}

\subsection{Moisture Damage Assessment using Surface Energy}

The SFE components of the neat $40 / 60$ pen binder and six mastics, calculated using the Wilhelmy plate method, are presented in Table 6 . The values of the surface energy components and total surface energy in $\mathrm{mJ} / \mathrm{m}^{2}$ are quoted up to one decimal point. The base bitumen (i.e. 40/60 Neat) used in this study is of a typical acidic nature which can be compared with the results other previous studies (Kakar et al. 2016; Nejad et al. 2013)

The results show that there was an increase of the basic component for the granite mastics when part of the granite filler was replaced with hydrated lime. However, for the limestone mastics, the same replacement only showed a marginal change. For the acidic component, there was a small reduction observed in most of the cases.

The surface energy components, total surface energy and specific surface area of the two aggregates used in this study are presented in Table 7.

The results in Table 7 show that the surface energies of the two aggregate types vary considerably. This difference is not only in terms of the total energy but also in terms of the 
surface energy components. This difference in the energy can be due to the fact that the different aggregate types vary considerably in composition depending on their source. This difference has a considerable effect on the adhesive properties when bitumen comes into contact with aggregates during the production of asphalt mixtures. If the components of SFE of granite are studied, it can be seen that the basic component is considerably higher than the acidic component, which may be contrary to what is expected for an 'acidic' igneous aggregate. However, this can happen as the surface chemistry and bulk chemistry of material could be different (Kim, 2009). In addition, the results from other research studies have shown the same type of variation in the acidic and basic components (Liu et al 2014; Grenfell et al 2014).

\subsubsection{Dry and wet work of adhesion}

The surface free energies of the bitumen/mastic and aggregates were used to determine the interfacial work of adhesion under dry conditions as well as the work of de-bonding under wet conditions. The values of the work of adhesion and debonding for all the combinations of bitumen/mastic and aggregates are presented in Figure 3. The results for the granite aggregates show that the work of adhesion has increased by about $9.5 \%$ with the replacement of $10 \% \mathrm{HL}$ with a greater increase of approximately $56 \%$ with $20 \%$ HL replacement. In terms of the work of de-bonding results, the results in Figure 3 show the work of de-bonding has decreased by $9 \%$ with the replacement of $10 \%$ HL with a larger decrease of $51 \%$ with $20 \%$ HL replacement. For the limestone aggregates, the replacement of HL in the mastics has not shown any positive results, both for the work of adhesion and the work of de-bonding. Although there are some differences noted between the neat bitumen and the other mastics, all the combinations of limestone mastics have almost the same work of adhesion and de-bonding.

\subsubsection{Energy parameters for moisture damage}

Little and Bhasin (2006) and Bhasin (2007) in studies on field moisture damage performance versus laboratory surface free energy and intrinsic adhesion defined a set of threshold values for all the energy parameters to separate 'good' and 'poor' performing binder-aggregate combinations against moisture damage performance. These threshold limits are 0.75 for $\mathrm{ER}_{1}$, 0.50 for $\mathrm{ER}_{2}, 0.50$ for $\mathrm{ER}_{3}$ and 0.35 for $\mathrm{ER}_{4}$. These surface energy parameters have been reported to be sensitive to the positive effect of anti-stripping agents on moisture resistance and have been used by various researchers to discriminate good and poor performing binder- 
aggregate combinations (Grenfell et al. 2014; Howson et al. 2012; Liu et al. 2013). Further more, it has been reported that SSA has a large influence on the moisture sensitivity of asphalt mixtures so the energy parameters ER3 and ER4 can be considered as more suitable indices for determining the performance of the different aggregate-bitumen combinations.

The values of all four energy parameters for the materials included in this study are presented in Table 8. These values are mentioned only as a reference. The threshold limits for the mastics will be different and can be quantified by conducting a study similar to Bhasin (2007) on the material under consideration. It can be observed that the replacement of granite filler with HL has shown improved results compared to the neat bitumen and the mastic having only granite filler. This is especially true in the case of the mastic having $20 \% \mathrm{HL}$, which showed a massive increase of over $200 \%$ in terms of all four energy parameters.

The energy ratio results for all the limestone combinations are very similar to each other. The addition of $10 \%$ HL has shown slightly better results, but $20 \%$ HL addition has decreased performance relative to both the $0 \% \mathrm{HL}$ and $10 \%$ HL mastics. Overall it can be concluded that there is practically no beneficial effect of HL addition on limestone aggregates based on these surface energy calculations.

\subsection{Moisture Damage Assessment using the RBT}

The rolling bottle test (RBT) was conducted in accordance with (BS EN 12697-11 (2012)). It is a measure of affinity between aggregate and bitumen and it also measures the susceptibility to stripping. The susceptibility to striping gives an indirect indication of the bond strength between the binder and the aggregate. This procedure can also be used to evaluate the effect of moisture for given binder and aggregate combinations as the loose coated aggregates are agitated in water for a certain period of time. The results are measured by visual inspection in terms of the degree of bitumen coating on loose bitumen coated aggregates after the influence of mechanical stirring in water.

Standard aggregate sizes of $10 \mathrm{~mm}-6.3 \mathrm{~mm}$ were used. Each aggregate type was tested with four combinations of binders including one neat 40/60 pen bitumen (40/60 Neat) and three mastics. A total of six different types of mastics were used in combination with the two types of aggregate. The notation, composition and the type of the aggregate used with these mastics 
are presented in Table 3. The test was conducted at an ambient temperature of $20^{\circ} \mathrm{C}$ which was maintained in the test location during testing.

The results for granite aggregates with different combinations of bitumen/mastics are presented in Figure 4. It can be evaluated that with time, the coating of the binder has decreased significantly especially for the $40 / 60$ pen bitumen and for the mastic containing $0 \%$ hydrated lime (50\% G). For the mastics having 10 and $20 \%$ hydrated lime, it can be seen that their retained percentage coating is considerably better than both the neat bitumen and the mastic with $0 \%$ HL. Although the mastic with $20 \%$ HL has shown slightly better results than the mastic with $10 \% \mathrm{HL}$, there is only a small difference between these two sets of results.

From the results of limestone aggregates presented in Figure 5, it can be seen that there is no significant difference between all three mastics and the 40/60 pen bitumen. In contrast to Figure 4, the mastic having $0 \%$ HL (50\% LS) performs slightly better than those containing $10 \%$ and $20 \%$ HL. There is a marginal difference between neat bitumen and all three mastics used in combination with the limestone aggregate. Based on these facts it can be concluded that hydrated lime does not appear to be beneficial in the case of the limestone aggregate.

To evaluate the performance of different aggregate types with and without HL, results after 72 hours are compared in Figure 6. They show a clear difference between the performance of the two aggregate types with their different combinations. By looking at the results for the granite aggregates it is clear that their performance was significantly affected by the use of mastic with HL. On the other hand, there was no significant difference observed in the results of RBT when limestone is used as the aggregate. With the use of $10 \% \mathrm{HL}$ in the mastic, the percentage retained coating increased to about $50 \%$ for granite aggregates in comparison with the mastic containing only granite filler. With the increase of HL from $10 \%$ to $20 \%$ in the mastic with granite aggregates, there is a small increase in percentage coating. This relatively small additional increase means it may not be cost effective to add $20 \% \mathrm{HL}$ in the mastic as the improvement in performance is only minor compared to the $10 \%$ HL addition.

\subsection{Moisture Damage Assessment using the PATTI Test}

To quantify the practical work of adhesion and any beneficial effect of HL in the mastics, the Pneumatic Adhesion Tensile Testing Instrument (PATTI) has been used. All the samples were tested after 0 and 7 days conditioning time under water at $20^{\circ} \mathrm{C}$. The decision to use 7 days 
conditioning was made based on the study of Zhang et al. (2015) on moisture damage assessment using the PATTI test where 7 and 14 days conditioning time was used and the results of both 7 and 14 days were shown to follow the same trend. So, it can be concluded that 7 days conditioning time can be considered as effective as 14 days for the assessment of moisture damage through PATTI testing.

Initially, testing was carried out with a granite substrate with four binder combinations and the samples were tested under dry conditions in accordance with the standard PATTI test. Conditioned samples were soaked in water for 7 days at $20^{\circ} \mathrm{C}$ and then tested within a few hours of taking them out of the water. The results for 0 and 7 days conditioning time are shown in Figure 7.

Results presented in Figure 7 show a high level of inconsistency, especially for the results shown in Figure $7 \mathrm{~b}$ for 7 days conditioning which showed a large degree of scatter in the results for some combinations. To achieve more consistency in the results, a new technique was introduced. In this technique, the samples were tested under water to prevent samples from becoming dried out. As shown in Figure 8, only the substrate and part of the pull off stub is submerged under the water and the rest of the procedure remains the same.

Testing was carried out on both granite and limestone substrates after 0 and 7 days water conditioning. For 0 days conditioning the samples were left in water for a period of 30-60 minutes. A comparison of the peak tensile strength between 0 and 7 days conditioning for the neat bitumen and the three mastic compositions with granite and limestone substrates was then undertaken. Error bars were also been plotted using the \pm 1 standard deviation calculation from the three trials for each combination.

The results seem to be quite consistent, but with some combinations, there is still a degree of variability between the three repeats. However, these results are far better than the results using the standard dry conditions during testing. Based on these results it can be deduced that the repeatability of the PATTI test under water is far better than under the standard conditions in which samples are tested out of the water. The previous statement is only true for moisture damage assessment when samples are conditioned for a specific duration in water and are tested for bond strength using the PATTI test. Despite the fact that the PATTI has slightly poor 
repeatability (Kanitpong and Bahia 2003), it is still a quick and useful tool to give an indication of adhesion failure.

The results for the granite aggregates are presented in Figure 9. In the dry condition, all three mastics are clearly performing better than the neat bitumen but the difference between the different types of mastic used with granite aggregate is not very distinct especially between the mastic having $0 \% \mathrm{HL}(50 \% \mathrm{G})$ and the mastic with $10 \% \mathrm{HL}(40 \% \mathrm{G}+10 \% \mathrm{HL})$. On comparing the $50 \% \mathrm{G}$ mastic with the $30 \% \mathrm{G}+20 \% \mathrm{HL}$ mastic there are some improvements which can be noted in the form of an $11 \%$ incremental increase in the average peak tensile strength value.

The results after 7 days conditioning in water are clearer and the beneficial effect of HL can be easily noted. Again, the mastics performed better than the neat bitumen. Performance of the two mastics having $0 \% \mathrm{HL}$ and 10\% HL was again similar but an increase of $40 \%$ was calculated in the average peak tensile strength between the mastic having 0\% HL and the one having 20\% HL. Although there is an increase in the average peak tensile strength in both the dry and wet condition with the addition of $10 \%$ HL to the mastic, it was not very distinctive. On the other hand, the addition of $20 \%$ HL shows a clear and distinctive difference in the average peak tensile strength compared to the mastic with $0 \%$ HL.

The reason for the increased peak tensile strength after zero and 7 days water conditioning for the granite mastics and its combinations with the hydrated lime can be explained by referring to the data in Table 6 . The surface energy components of the neat bitumen in Table 6 show that this bitumen is acidic in nature as the acidic component of the surface energy is greater than its basic component. With the addition of $50 \%$ granite filler, there was an increase in the basic component of the surface energy observed while a decrease was observed for the acidic component. Similarly, the addition of $40 \%$ granite filler and $10 \%$ HL, to form a mastic, resulted in a further increase of the basic component of SFE and a further reduction in its acidic component. The trend continued with the use of filler having $30 \% \mathrm{G}$ and $20 \% \mathrm{HL}$ and the mastic displayed an even higher basic component of SFE and similarly, the acidic component was further reduced. This increase in the basic component of SFE and decrease in the acidic component makes the bitumen/mastic more favourable to forming a strong bond with the acidic aggregates. This improved adhesion was observed in all three mastics used with the granite aggregates compared to the neat bitumen, especially the mastics containing HL. 
The results for the limestone aggregate combinations after 0 and 7 days conditioning in water are presented in Figure 10. The results for the samples tested after 0 days conditioning in water look very similar for the three mastic combinations. Although there is a clear increase in the average pull-off strength for the mastic combinations compared to neat bitumen there is hardly any difference between the different mastics used with the limestone aggregate substrate. The results for the samples tested after 7 days conditioning look similar to 0 days conditioning as again the average peak tensile strength for the three mastics is in a very narrow band. So, based on these results, it is difficult to deduce that there is any beneficial effect of HL observed with this particular limestone.

The above results can be explained further by correlating them with the surface energy results (Table 6). There was an increase in the basic component of the mastic having $50 \%$ LS filler and a decrease in the acidic component compared to the neat bitumen. Also, in the mastic having $40 \%$ LS filler and 10\% HL, the basic component was further increased but only a very slight change was observed in the acidic component. With the use of $30 \%$ LS filler and $20 \%$ HL in the mastic, an unusual drop in the basic component was observed, while the acidic component also decreased slightly. So, based on the surface energy results it can be concluded that the increase in the basic component of the bitumen with the addition of filler will not result in an improved bond strength if used with limestone aggregates which are already basic in nature. As the use of LS or HL filler makes the bitumen even more basic in nature, the adhesion will not improve if used in combination with limestone aggregates.

Based on the above results it can be deduced that HL is not always beneficial for adhesion and it is the type of aggregate that decides and defines its efficiency. To conclude, with this particular testing technique, HL shows the best performance with granite while limestone does not show any beneficial effect with the presence of HL.

\section{Discussion}

As already discussed, the main objective of this research was to quantify the bond strength of hydrated lime modified mastics with two aggregates under moisture conditions using a combination of surface free energy techniques and conventional adhesion test methods which includes the RBT and PATTI tests. A complete characterization was possible once results from SFE measurements and calculations were compared with those of conventional adhesion tests 
available for moisture susceptibility analysis. Figure 11 and 12 show a comparison between RBT per cent retained binder coverage, energy ratio $\mathrm{ER}_{4}$ and PATTI retained strength (ratio of peak tensile strength of conditioned and unconditioned sample) for granite and limestone aggregates respectively. A higher value of energy ratio means better moisture damage resistance. On this basis, the combination on the top right will have better moisture damage performance compared to the one near the bottom left. For the granite aggregate, it can be seen from Figure 11 that its performance with the mastic without HL is not good. With the addition of $10 \% \mathrm{HL}$, there is an improvement in the moisture damage performance which becomes significant with the addition of $20 \%$ HL to the binder. Performance of the limestone aggregates on the other hand does not appear to be significantly influenced by the addition of $10 \%$ or $20 \%$ HL as depicted in Figure 12. The results clearly illustrate a close agreement between all three techniques used in this study for evaluation of moisture susceptibility. The results presented in this study are also in line with some of the previous studies on asphalt mixtures where beneficial effects of HL have been found to be aggregate dependent (Airey et al. 2008; Dony et al. 2012).

Improvement in the moisture damage performance of granite aggregate combinations can be attributed to a change in physico-chemical characteristic of the mastic with HL which resulted in an increased basic component when part of the granite filler was replaced with hydrated lime. This increase in the basic component made the mastic more favourable for acidic natured granite aggregates. In the limestone mastics, the same replacement only showed a marginal change in contrast. Improved moisture susceptibility of one aggregate combination compared to the other could also be due to the difference in the mineralogy. Mineralogical testing of the aggregates, using MLA, showed considerable differences between granite and limestone. Granite aggregates were found to be rich in albite, epidote, quartz and chlorite minerals. The calcite mineral was found to be predominate in the limestone aggregates. It has been observed in past studies that aggregates with large albite and quartz content have a poor moisture resistance compared to those with predominate calcite content (Apeagyei et al. 2014; Zhang et al. 2015). By looking at the MLA results presented in Table 1, it can be seen why the moisture damage performance of the granite aggregates is inferior in comparison to limestone as deteremined by the SFE, PATTI and RBT testing techniques. This is due to the presence of a high proportion of albite and quartz as reported in the literature. A significant improvement in moisture susceptibility of the granite combination could be due to the fact that when HL is present in the mastic, calcium ions accumulate at the aggregate surface and react with the acids from the bitumen to make a water-insoluble salt. With the formation of this insoluble salt on 
the surface of aggregate, surface roughness increases which favours aggregate-bitumen adhesion (Blazek et al. 2000). In limestone aggregate, the lack of accumulation of calcium ions due to its basic nature could explain why HL modified mastic when used with limestone aggregate didn't produce an additional beneficial effect which can be clearly seen in the results from the SFE and adhesion test techniques.

\section{Conclusions}

Three test techniques were used in this paper to evaluate the performance of HL on the moisture susceptibility of asphalt mixtures consisting of SFE measurements of the individual components (aggregate, bitumen and mastic) and adhesion tests using the RBT and PATTI procedures. The following conclusions can be draw based on the results presented in this paper:

- Results from the surface energy testing in the form of work of adhesion, work of debonding and four energy parameters were found to be sensitive to material type. For the granite aggregate, there was a clear incremental increase in the performance observed with the addition of HL to the mastic. There were some positive trends even with the lower $10 \%$ HL replacement, but the use of higher $20 \%$ HL content showed a significant improvement in the results. Limestone aggregates, on the other hand, did not show any improvement in the results obtained from SFE testing.

- The rolling bottle test was successfully performed on all the combinations used in the study and was extremely useful in discriminating different combinations. The beneficial effects of HL addition were clearly observed with granite although the limestone aggregates did not respond to the addition of HL when tested with the rolling bottle test.

- The PATTI test was used to determine the practical work of adhesion. To reduce the poor repeatability of the PATTI test, samples were successfully tested under water and results were found to be a lot better in terms of repeatability.

- $\quad$ The PATTI test was able to demonstrate improvements in moisture susceptibility performance for granite aggregates when tested with HL modified mastics. Though there was some improvement found with the use of $10 \% \mathrm{HL}$ in the mastic, the $20 \% \mathrm{HL}$ mastic showed a marked improvement. Limestone aggregates again did not respond to the HL substitution. 
- $\quad$ Overall, the granite aggregate showed optimum performance with $20 \% \mathrm{HL}$ in the mastic for two of the three test techniques, namely the surface energy approach and the PATTI test. With the rolling bottle test technique, the optimum HL content was found to be $10 \%$. In general, the results of three test techniques seem to indicate that $20 \% \mathrm{HL}$ can be considered to be an optimum HL content.

- The limestone aggregate has found to perform very similarly with or without HL addition in the mastic for all three test techniques. So, based on the results of the limestone aggregate used in this study, it can be stated that HL does not improve the moisture susceptibility performance of limestone aggregates.

- The effect of HL was found to be aggregate type dependent. The use of HL with granite aggregate showed an improvement in the performance against moisture damage and all the test methods used in the study supported this observation. Limestone aggregate did not respond to the addition of HL based on the results from the techniques considered in this research study.

- $\quad$ Mineralogical testing of the aggregates, using MLA, showed considerable differences between granite and limestone. The different behaviour of the two aggregates types to the HL modified mastics can be attributed in part to aggregate mineralogy.

- $\quad$ The ranking obtained in the RBT and PATTI techniques is similar to surface energy. The results clearly illustrate a close agreement between all three techniques used in this study for the evaluation of moisture susceptibility.

\section{References}

Adamson, A.W. and Gast, A.P. (1997). Physical Chemistry of Surfaces", 6th edition. New York: John Wiley and Sons, Inc.

Airey, G.D. and Choi, Y-K. 2002. 'State of the Art Report on Moisture Sensitivity Test Methods for Bituminous Pavement Materials.' International Journal of Road Materials and Pavement Design, Vol. 3, No. 4, pp 355-372.

Airey, G.D., Collop, A.C., Zoorob, S.E. and Elliott, R.C. 2008. 'The influence of aggregate, filler and bitumen on asphalt mixture moisture damage.' Construction and Building Materials, Vol. 22, No. 9, pp 2015-2024. 
Apeagyei, A.K., Grenfell, J.R.A. and Airey, G.D. 2014. 'Moisture-induced strength degradation of aggregate-asphalt mastic bonds.' Road Materials and Pavement Design, Vol. 15, No. S1, pp 239-262.

Bhasin, A., Masad, E., Little, D. and Lytton, R. 2006. Limits on Adhesive Bond Energy for Improved Resistance of Hot-Mix Asphalt to Moisture Damage. Transportation Research Record 1970, 3-13.

Bhasin, A. (2007). "Development of methods to quantify bitumen-aggregate adhesion and loss of adhesion due to water." Texas A\&M University.

Bhasin, A. and Little, D. (2007). Charactization of aggregate surface energy using the universal sorption device. Journal of Materials in Civil Engineering, 19, 634-641.

Blazek, J., Sebor, G., Maxa, D., Ajib, M. and Paniagua, H. (2000). "Effect of hydrated lime addition on properties of asphalt." Petroleum and Coal, 42(1), 41-45.

BS EN 12697-11 (2012). "Bituminous Mixtures - Test Methods for Hot Mix Asphalt - Part 11: Determination of the Affinity Between Aggregate and Bitumen." London.

Cheng, D., Little, D.N., Lytton, R.L. and Holste, J.C. 2002a. Use of Surface Free Energy of Asphalt-Aggregate System to Predict Moisture Damage Potential. Journal of the Association of Asphalt Paving Technologists, 71, 59-88.

Cheng, D., Little, D.N., Lytton, R.L. and Holste, J.C. 2003. Moisture Damage Evaluation of Asphalt Mixtures by Considering Both Moisture Diffusion and Repeated-Load Conditions, Transportation Research Record, Vol. 1832, pp. 42-49.

Dony, A., Johan, C., Charley, T. and Didier, L. (2012) "Effect of hydrated lime on the resistance of asphalt mixtures to winter-related damage: Moisture, freeze-thaw and deicing salts." Proc., 5th Eurasphalt and Eurobitume Conference.

Faheem, A., Bahia, H., Hintz, C., Al-Qadi, I., Reinke, G. and Dukatz, E. (2011). "Test Methods and Specification Criteria for Mineral Filler Used in HMA." Final Report, 9-45.

Good, R.J. (1966). Intermolecular and interatomic forces. In Patrick, R.L (Ed.), Treatsie on adhesion and adhesives, Volume 1: Theory (pp. 10-65). New York: Marcel Dekker, Inc.

Grenfell J.R.A., Ahmad N., Liu Y., Apeagyei A.K., Large D. and Airey G.D. (2014). Assessing asphalt mixture moisture susceptibility through intrinsic adhesion, bitumen stripping and mechanical damage. Road Materials and Pavement Design, 15(1), 131-152.

Grenfell J.R.A., Ahmad N., Airey G.D., Collop A.C. and Elliott R.C. (2012). Optimising the moisture durability SATS conditioning parameters for universal asphalt mixture application. International Journal of Pavement Engineering, 13(5), 433-450. 
Hesami, S., Roshani, H., Hamedi, G. H. and Azarhoosh, A. (2013). "Evaluate the mechanism of the effect of hydrated lime on moisture damage of warm mix asphalt." Construction and Building Materials, 47, 935-941.

Hicks, R. and Scholz, T. (2003). "Life Cycle Costs for Lime in Hot Mix Asphalt, Volume 3." Arlington (Virginia, USA): National Lime Association.

Howson, J., Masad, E., Little, D. and Kassem, E. (2012). "Relationship between bond energy and total work of fracture for asphalt binder-aggregate systems." Road Materials and Pavement Design, 13(sup1), 281-303.

Kakar, M. R., Hamzah, M. O., Akhtar, M. N. and Woodward, D. (2016). "Surface free energy and moisture susceptibility evaluation of asphalt binders modified with surfactant-based chemical additive." Journal of cleaner production, 112, 2342-2353.

Kandhal, P. and Rickards, I. (2001). "Premature failure of asphalt overlays from stripping: Case histories." Asphalt Paving Technology, 70, 301-351.

Kanitpong, K. and Bahia, H.U. (2003). "Role of adhesion and thin film tackiness of asphalt binders in moisture damage of HMA." Asphalt Paving Technology, 72, 201-241.

Kim, Y.-R., Lutif, J.S., Bhasin, A. and Little, D.N. (2008). "Evaluation of moisture damage mechanisms and effects of hydrated lime in asphalt mixtures through measurements of mixture component properties and performance testing." Journal of Materials in Civil Engineering, 20(10), 659-667.

Kim, Y. R. (2009). Modelling of Asphalt Concrete, McGraw-Hill Construction, ASCE Press USA.

Lesueur D., Petit J. and Ritter H.J. (2013): The Mechanisms of Hydrated Lime Modification of Asphalt Mixtures: A State-of-the-Art Review, Road Materials and Pavement Design, 14:1, $1-16$.

Little, D.N. and Bhasin, A. (2006). "Using Surface Energy Measurements to Select Materials for Asphalt Pavement." National Cooperative Highways Research Program, Transportation Research Board, Washington DC, USA, Final Report for NCHRP 9-37.

Liu, Y., Apeagyei, A.K., Ahmad, N., Grenfell, J.R.A. and Airey, G.D. 2014. 'Examination of moisture sensitivity of aggregate-bitumen bonding strength using loose asphalt mixture and physico-chemical surface energy property tests.' International Journal of Pavement Engineering, Vol. 15, No. 7, pp 657-670.

Maldonaldo, R. (2008) "Bitumen modification with polyphosphoric acid." Proceedings of the 4th Eurasphalt and Eurobitume Congress, Copenhagen, Denmark. 
Masad, E.A., Zollinger, C., Bulut, R., Little, D.N. and Lytton, R.L. 2006. Characterization of HMA Moisture Damage Using Surface Energy and Fracture Properties. Journal of the Association of Asphalt Paving Technologists, 75, 713-754.

Mohammad, L. N., Saadeh, S., Kabir, M., Othman, A. and Cooper, S. (2008). "Mechanistic properties of hot-mix asphalt mixtures containing hydrated lime." Transportation Research Record: Journal of the Transportation Research Board, 2051(1), 49-63.

Miller, J.S. and Bellinger, W.Y. (2003) Distress Identification Manual for the Long-Term Pavement Performance Program. Publication FHWA-RD-03-031. FHWA, Office of Infrastructure Research and Development, McLean, Virginia.

Nejad, M., F., Hamedi, G.H. and Azarhoosh, A.R. (2013). "Use of Surface Free Energy Method to Evaluate Effect of Hydrate Lime on Moisture Damage in Hot-Mix Asphalt." Journal of Materials in Civil Engineering, 25(8), 1119-1126.

Santagata, F., Cardone, F., Canestrari, F. and Bahia, H.U. 2009. "Modified PATTI test for the characterization of adhesion and cohesion properties of asphalt binders." Proceedings of the Sixth International Conference on Maintenance and Rehabilitation of Pavements and Technological Control, Turin.

Schultz, J. and Nardin, M. (1994). Theories and mechanisms of adhesion. In A. Pizzi and K.L. Mittal (Eds.), Handbook of Adhesive Technology (pp. 19-33). New York: Marcell Dekker, Inc. Sebaaly, P., Little, D. and Epps, J. (2006). "The benefits of hydrated lime in hot mix asphalt." Arlington (Virginia, USA): National Lime Association.

Van Oss, C.J., Chaudhury, M.K. and Good, R.J. (1988) Interfacial Lifshitz-van der Waals and Polar Interactions in Macroscopic Systems, Chem. Rev. Vol. 88, pp. 927-941.

Wang, H., Al-Qadi, I. L., Faheem, A. F., Bahia, H. U., Yang, S.-H. and Reinke, G. H. (2011). "Effect of mineral filler characteristics on asphalt mastic and mixture rutting potential." Transportation Research Record, 2208(1), 33-39.

Zhang, J., Airey, G.D., Grenfell, J. and Yao, Z. (2017). "Laboratory evaluation of Rediset modified bitumen based on rheology and adhesion properties." Construction and Building Materials, 152, 683-692.

Zhang J., Apeagyei A.K., Airey G.D. and Grenfell J.R.A. (2015). Influence of aggregate mineralogical composition on water resistance of aggregate-bitumen adhesion. International Journal of Adhesion and Adhesives, 62, 45-54. 


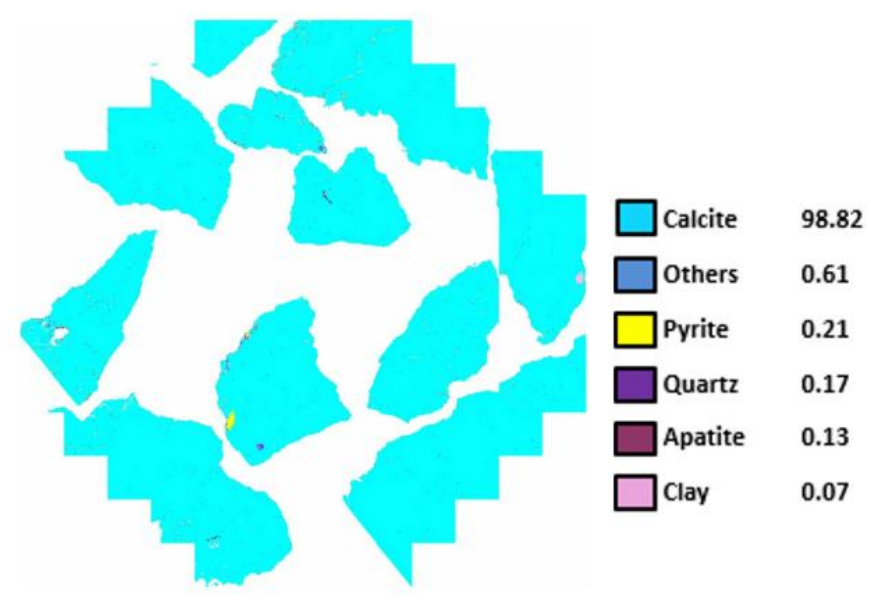

Figure 1: Mineral composition of limestone using MLA analysis
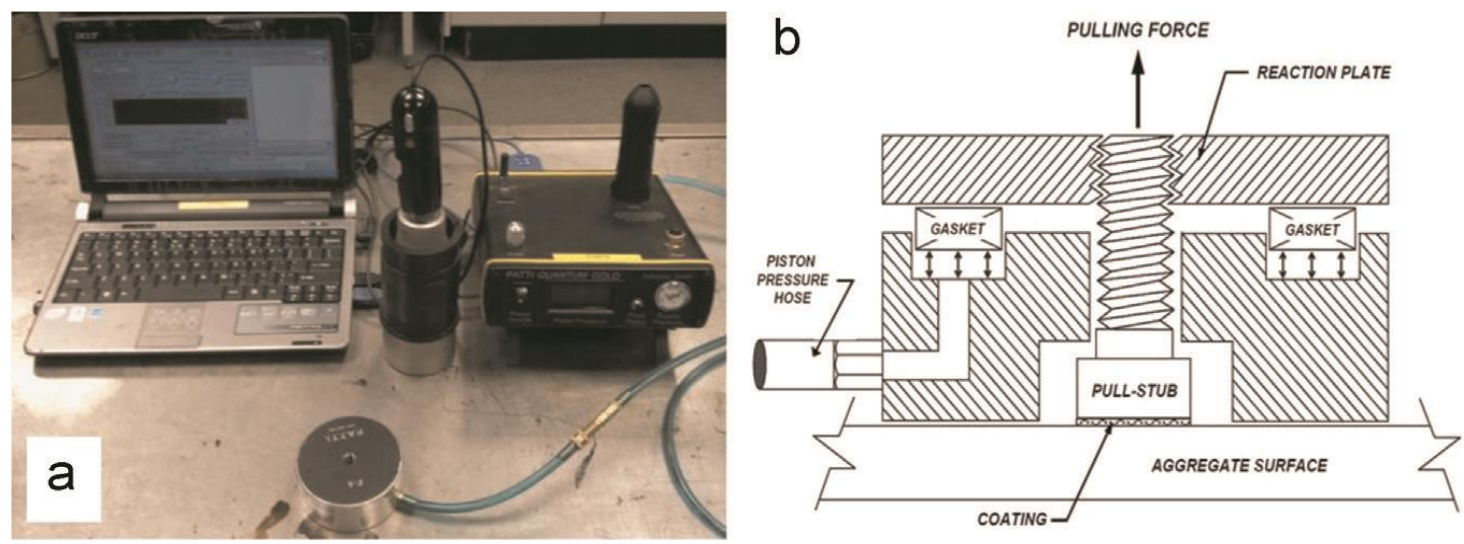

Figure 2: PATTI test: (a) set-up (b) cross-section view of piston attached to pull-stub (Santagata et al. 2009) 
Work of adhesion

Granite

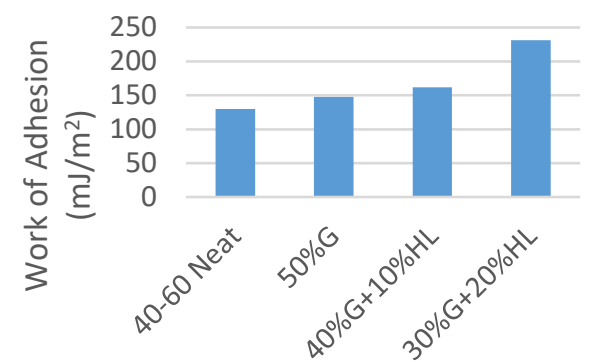

Limestone

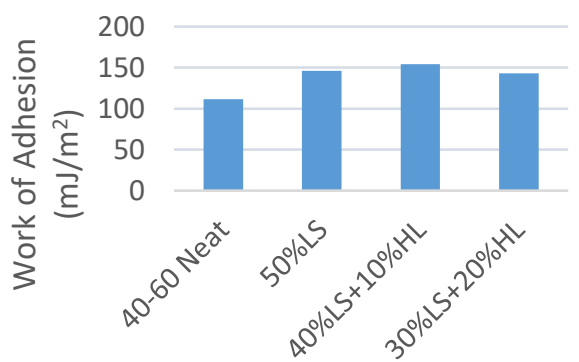

Work of de-bonding

Granite

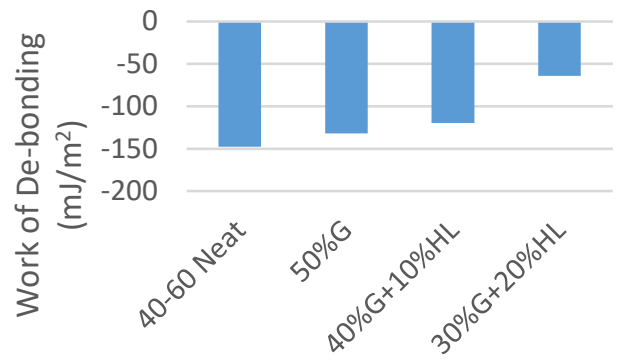

Limestone

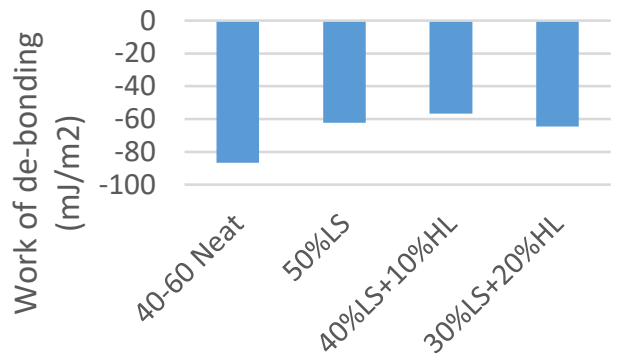

Figure 3: Work of adhesion and work of de-bonding for bitumen/mastics and aggregate combinations 


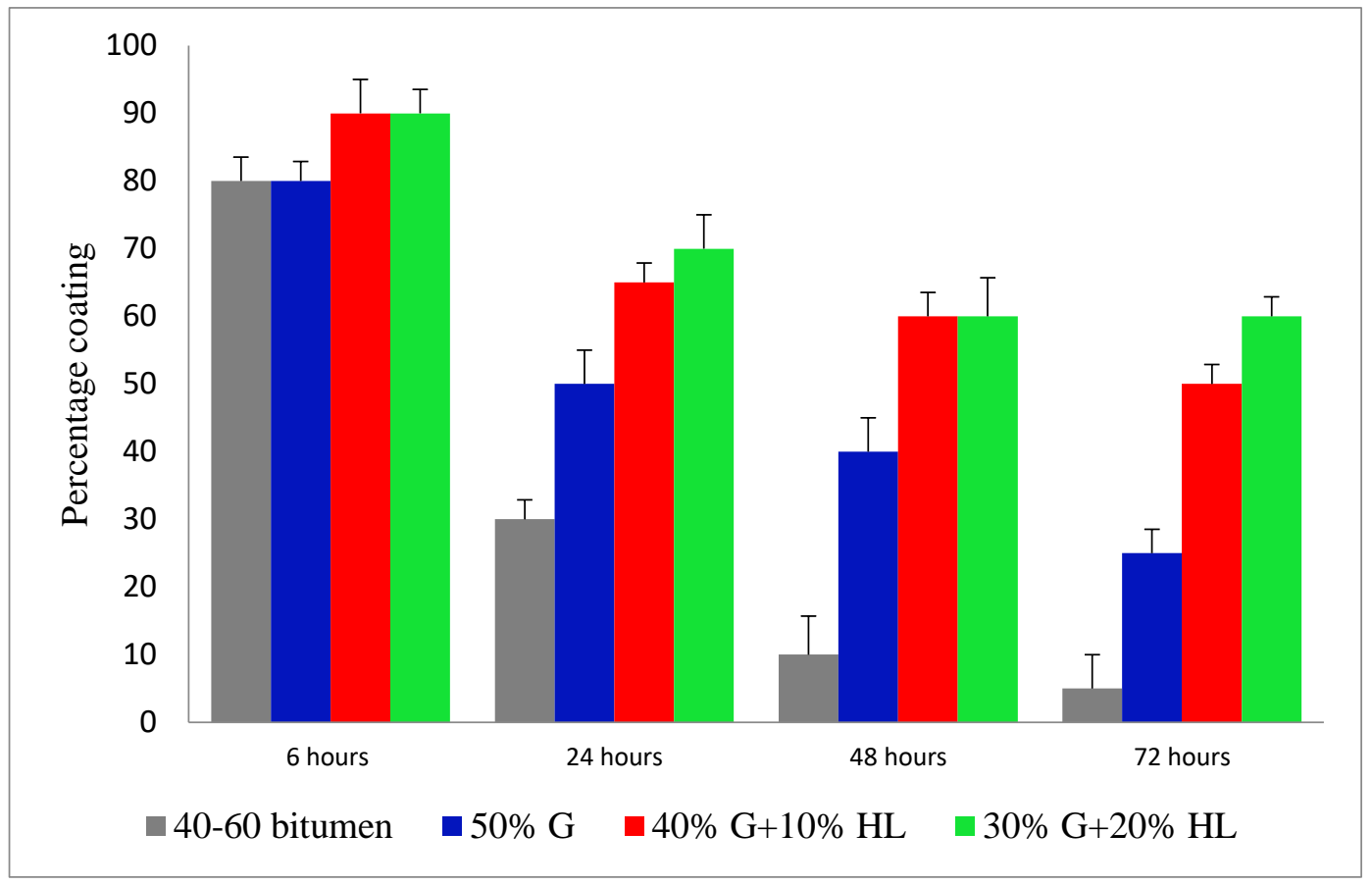

Figure 4: RBT test results for all combinations of granite aggregates

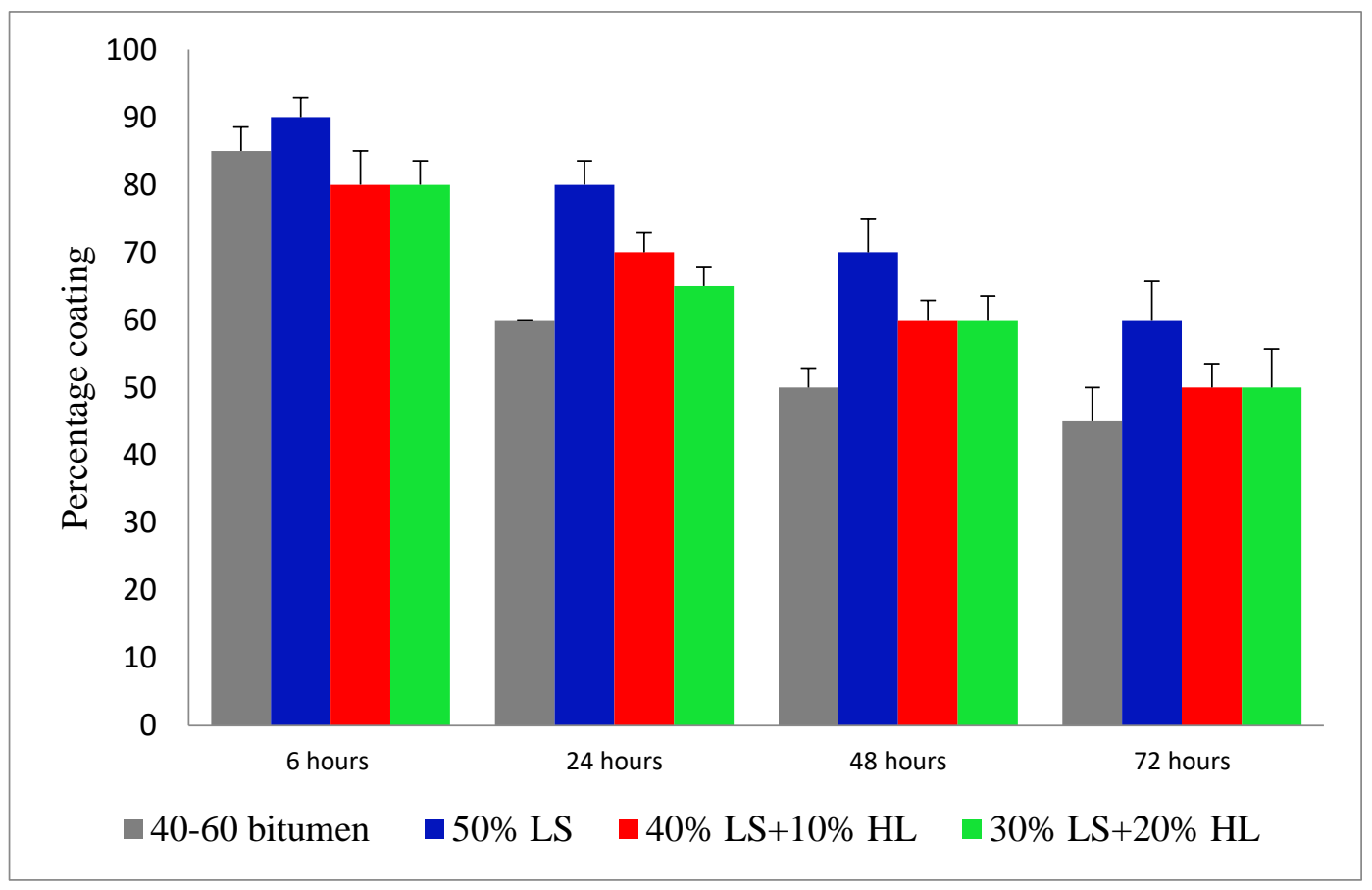

Figure 5: RBT test results for all combinations of limestone aggregates 


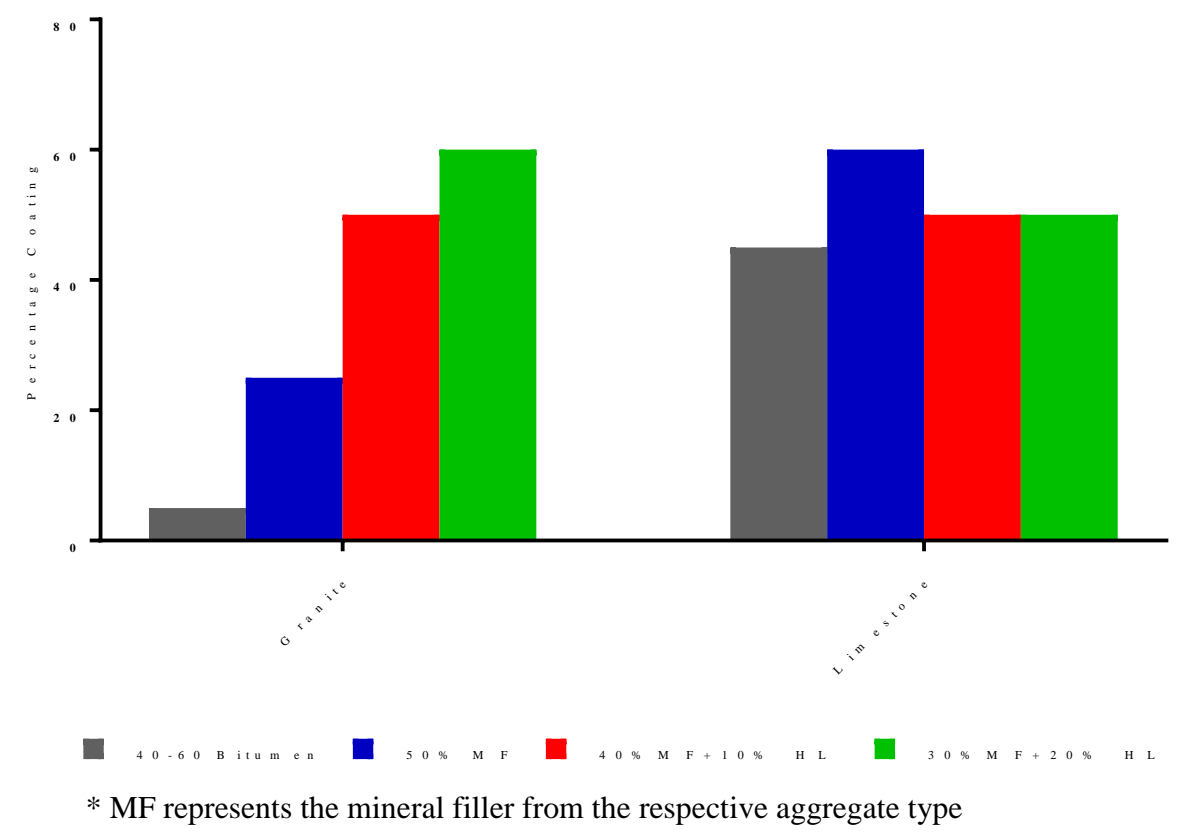

Figure 6: Comparison for RBT results after 72 hours between all aggregate combinations

A

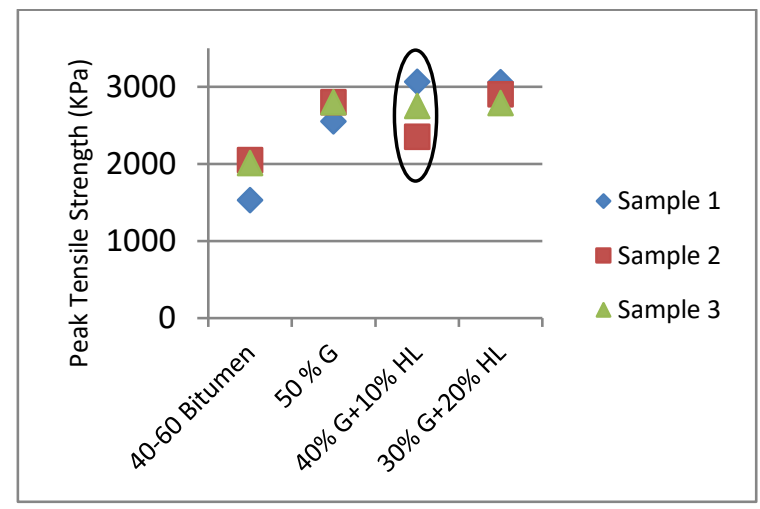

b

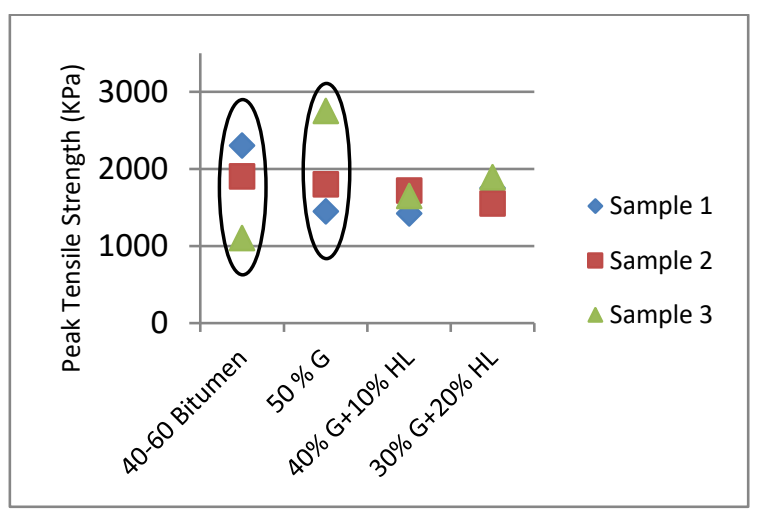

Figure 7: Standard PATTI test results with granite for a) 0 days conditioning b) 7 days conditioning 


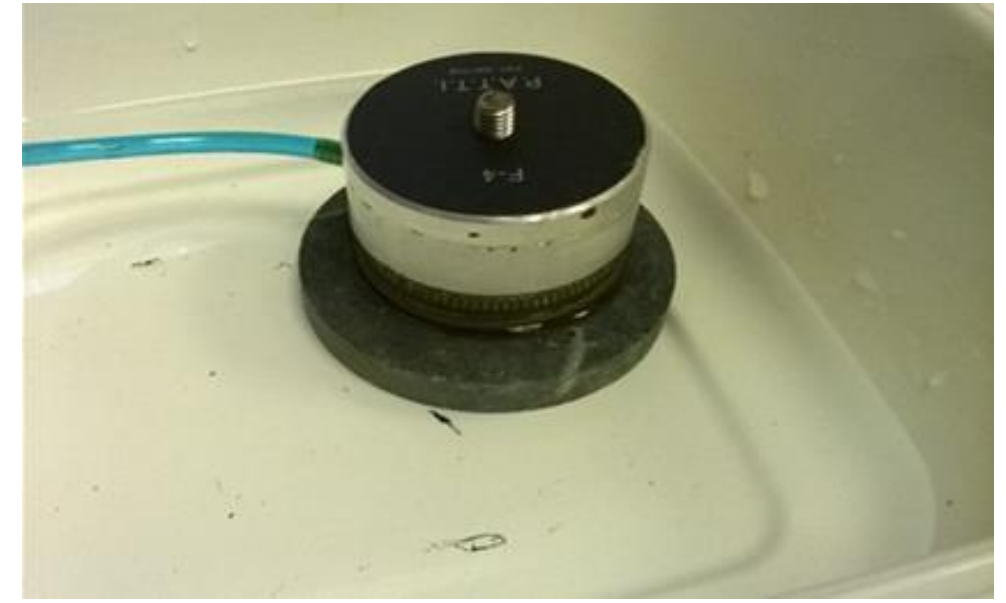

Figure 8: PATTI test, substrate and pull off stub submerged in water and other test assembly

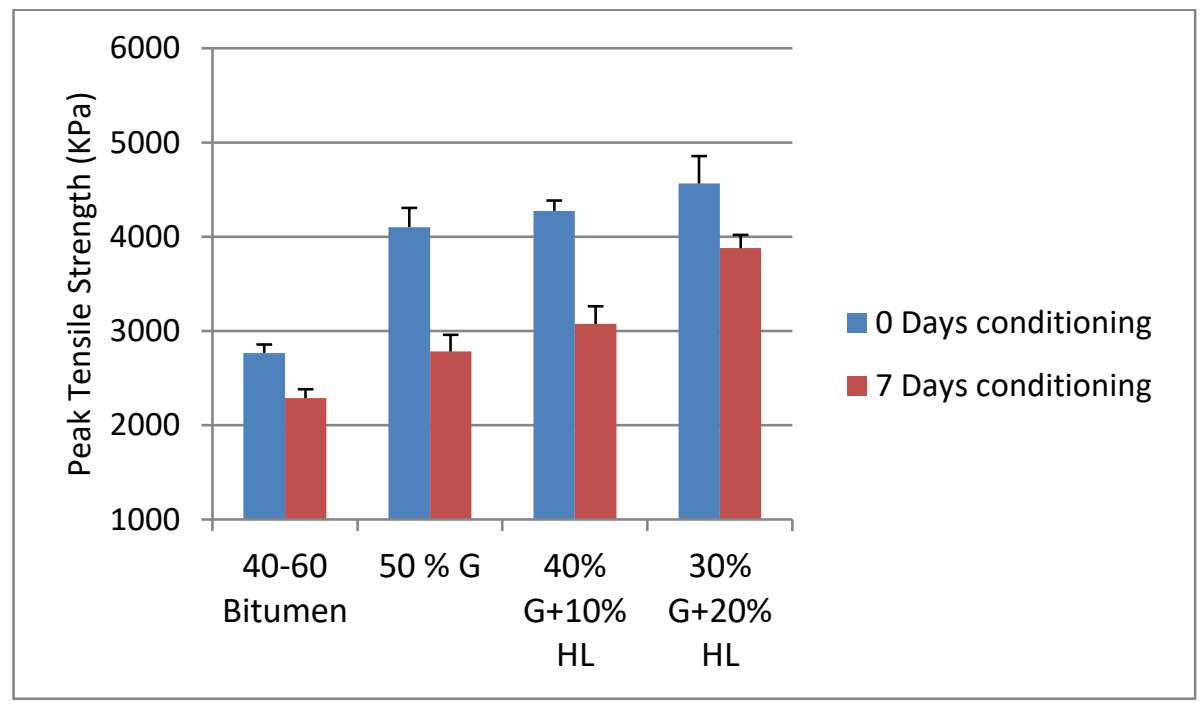

Figure 9: PATTI results under water for 0 and 7 Days conditioning with granite substrate 


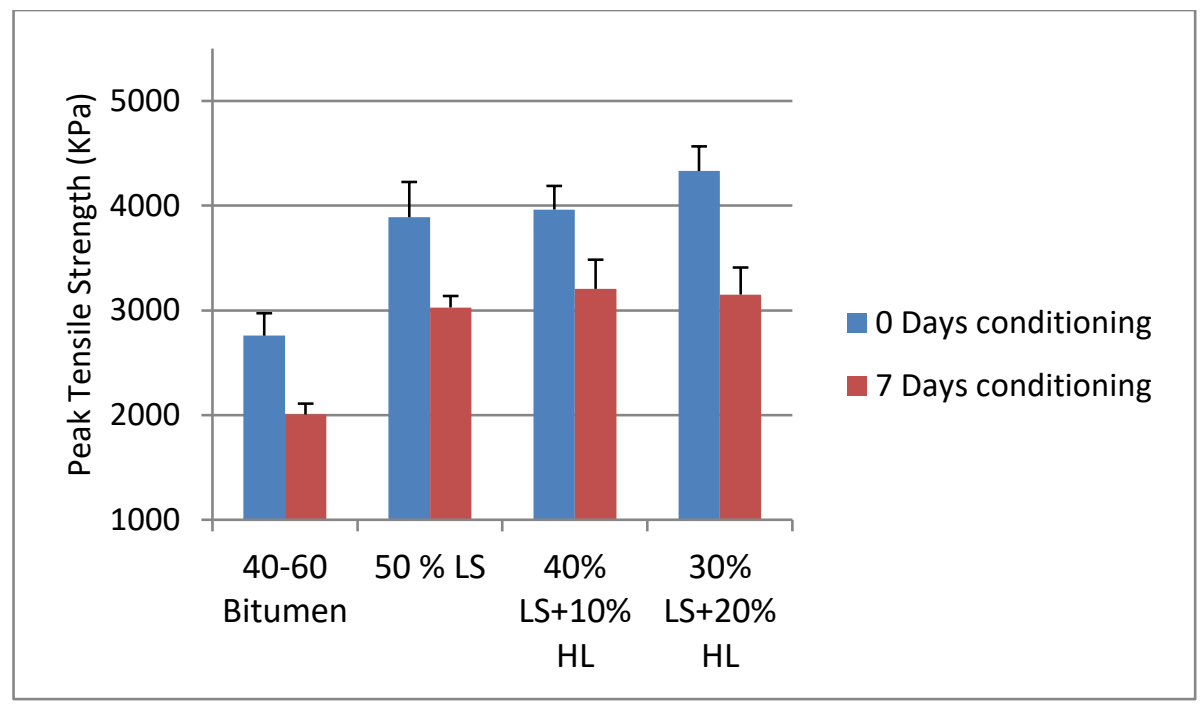

Figure 10: PATTI results under water for 0 and 7 Days conditioning with limestone substrate

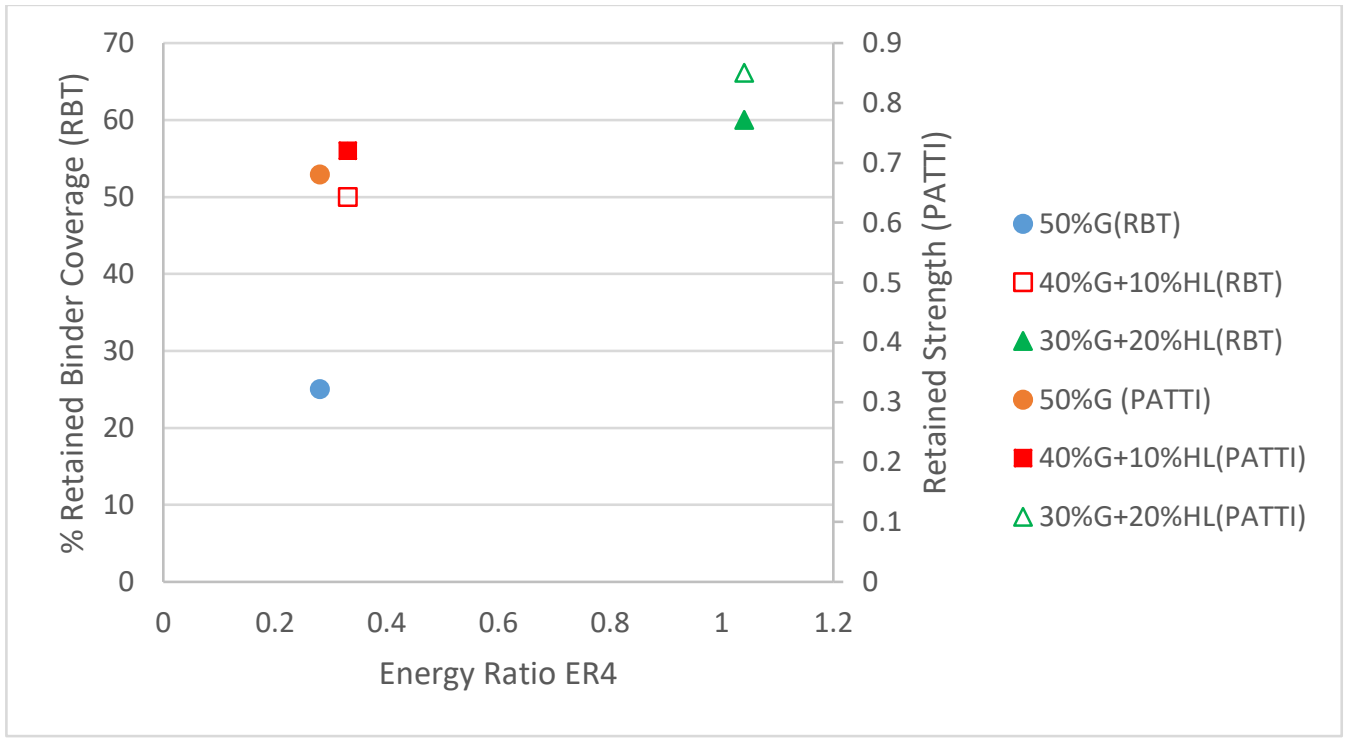

Figure 11: Comparison between RBT, SFE and PATTI techniques for granite aggregates 


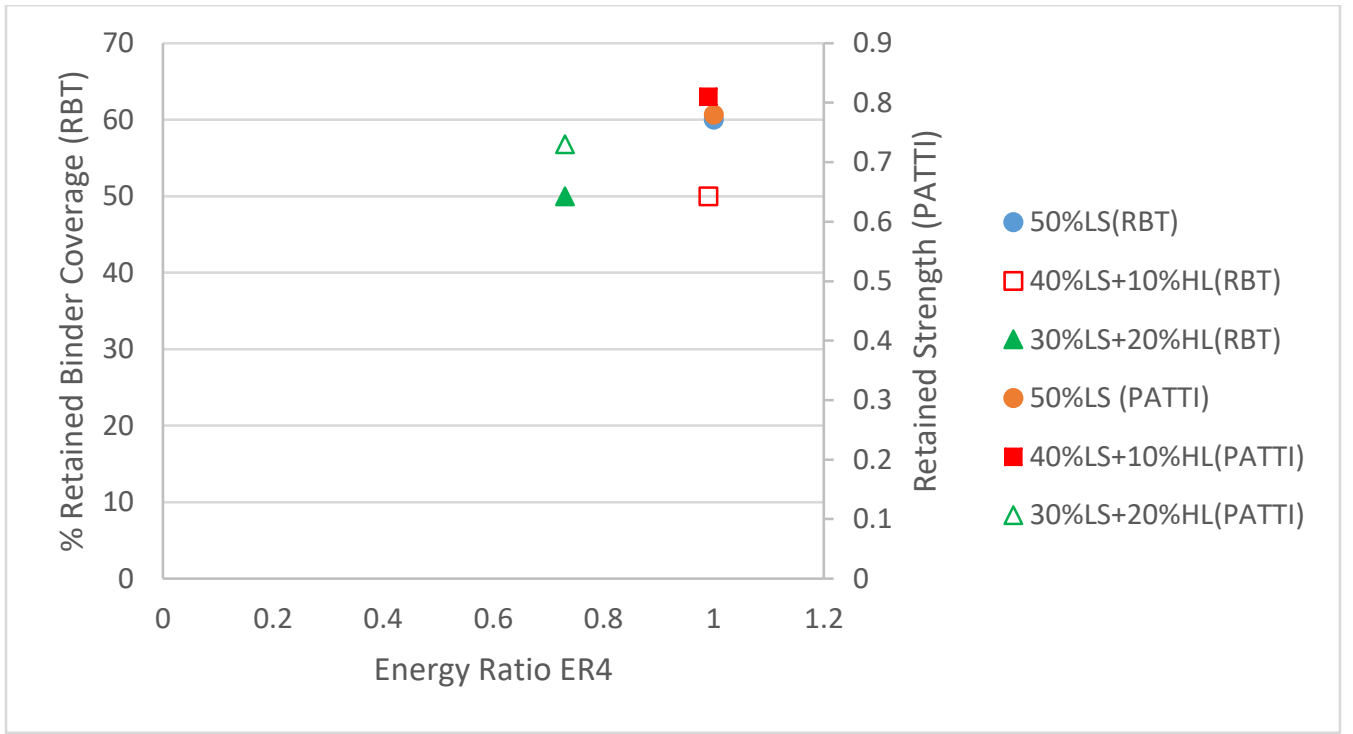

Figure 12: Comparison between RBT, SFE and PATTI techniques for limestone aggregates 
Table 1: Aggregate minerology through MLA

\begin{tabular}{|c|c|}
\hline Mineral Name & Composition (\%) \\
\hline Albite & 27.25 \\
\hline Epidote_group & 23.03 \\
\hline Quartz & 21.31 \\
\hline Chlorite & 16.67 \\
\hline K-feldspar & 6.01 \\
\hline Illite & 3.15 \\
\hline Biotite_group & 1.55 \\
\hline Titanite & 0.47 \\
\hline Others & 0.54 \\
\hline & \\
\hline Calcite & 98.82 \\
\hline Pyrite & 0.21 \\
\hline Quartz & 0.17 \\
\hline Apatite & 0.13 \\
\hline Clay & 0.07 \\
\hline Others & 0.61 \\
\hline
\end{tabular}


Table 2: Filler properties

\begin{tabular}{|l|l|l|l|}
\hline & Granite $(\mathrm{G})$ & Limestone $(\mathrm{LS})$ & $\begin{array}{l}\text { Hydrated Lime } \\
(\mathrm{HL})\end{array}$ \\
\hline Specific Gravity $\left(\mathrm{Mg} / \mathrm{m}^{3}\right)$ & 2.66 & 2.65 & 2.22 \\
\hline Surface area $\left(\mathrm{m}^{2} / \mathrm{g}\right)$ & 1.26 & 1.58 & 2.24 \\
\hline Rigden voids $(\%)$ & 46.94 & 39.82 & 61.62 \\
\hline
\end{tabular}


Table 3: Mastic notation, composition and type of aggregate used in combination with mastic

\begin{tabular}{|l|l|c|}
\hline Mastic Notation & Composition (by mass) & Aggregate \\
\hline $50 \% \mathrm{G}$ & $50 \%$ granite filler $+50 \% 40 / 60$ pen neat bitumen & Granite \\
\hline $40 \% \mathrm{G}+10 \% \mathrm{HL}$ & $\begin{array}{l}40 \% \text { granite filler }+10 \% \text { Hydrated lime }+50 \% 40 / 60 \text { pen } \\
\text { neat bitumen }\end{array}$ & Granite \\
\hline $30 \% \mathrm{G}+20 \% \mathrm{HL}$ & $\begin{array}{l}30 \% \text { granite filler }+20 \% \text { Hydrated lime }+50 \% 40 / 60 \text { pen } \\
\text { neat bitumen }\end{array}$ & Granite \\
\hline $50 \% \mathrm{LS}$ & $\begin{array}{l}50 \% \text { limestone filler }+50 \% 40 / 60 \text { pen neat bitumen } \\
40 \% \mathrm{LS}+10 \% \mathrm{HL}\end{array}$ & $\begin{array}{l}\text { Limestone } \\
\text { pen neat bitumen }\end{array}$ \\
\hline $30 \% \mathrm{LS}+20 \% \mathrm{HL}$ & $\begin{array}{l}30 \% \text { limestone filler }+20 \% \text { Hydrated lime }+50 \% 40 / 60 \\
\text { pen neat bitumen }\end{array}$ & Limestone \\
\hline
\end{tabular}


Table 4: Surface energy components for the probe liquids used for DCA

\begin{tabular}{|l|c|c|c|c|}
\hline Surface Energy & $\gamma_{\mathrm{L}}$ & $\gamma_{\mathrm{L}}^{\mathrm{LW}}$ & $\gamma_{\mathrm{L}}{ }^{+}$ & $\gamma_{\mathrm{L}^{-}}$ \\
\hline Water & 72.8 & 21.8 & 25.5 & 25.5 \\
\hline Glycerol & 64 & 34 & 3.92 & 57.4 \\
\hline Diiodomethane & 50.8 & 50.8 & 0 & 0 \\
\hline
\end{tabular}


Table 5: Surface energy components for the probe liquids used for DVS

\begin{tabular}{|l|c|c|c|c|}
\hline Surface Energy & $\gamma_{\mathrm{L}}$ & $\gamma_{\mathrm{L}}{ }^{\mathrm{LW}}$ & $\gamma_{\mathrm{L}^{+}}$ & $\gamma_{\mathrm{L}^{-}}$ \\
\hline Octane & 21.62 & 0 & 0 & 21.62 \\
\hline Ethyl acetate & 23.90 & 0 & 19.20 & 23.90 \\
\hline Chloroform & 27.15 & 3.80 & 0 & 27.15 \\
\hline Water & 72.80 & 21.80 & 25.50 & 25.50 \\
\hline
\end{tabular}


Table 6: Surface free energy components of all bitumen/ mastic samples

\begin{tabular}{|c|c|c|c|c|}
\hline \multirow[t]{2}{*}{ Bitumen/Mastic } & \multicolumn{3}{|c|}{ Surface Energy Components $\left(\mathrm{mJ} / \mathrm{m}^{2}\right)$} & \multirow{2}{*}{$\begin{array}{c}\text { Total Surface } \\
\text { Energy } \\
\gamma\left(\mathrm{mJ} / \mathrm{m}^{2}\right)\end{array}$} \\
\hline & $\gamma^{\mathrm{LW}}$ & $\gamma^{+}$ & $\gamma^{-}$ & \\
\hline $40-60$ Neat & 19.0 & 1.3 & 1.0 & 21.3 \\
\hline $50 \% \mathrm{G}$ & 23.7 & 0.4 & 1.7 & 25.2 \\
\hline $40 \% \mathrm{G}+10 \% \mathrm{HL}$ & 28.1 & 0.0 & 2.3 & 28.4 \\
\hline $30 \% \mathrm{G}+20 \% \mathrm{HL}$ & 28.7 & 0.0 & 8.9 & 28.7 \\
\hline $50 \% \mathrm{LS}$ & 36.6 & 0.1 & 1.5 & 37.5 \\
\hline $40 \% \mathrm{LS}+10 \% \mathrm{HL}$ & 36.7 & 0.2 & 2.0 & 37.9 \\
\hline $30 \% \mathrm{LS}+20 \% \mathrm{HL}$ & 38.0 & 0.1 & 1.2 & 38.7 \\
\hline
\end{tabular}


Table 7: Surface free energy components of all aggregate types

\begin{tabular}{|l|c|c|c|c|c|}
\hline Aggregates & \multicolumn{2}{|c|}{ Surface energy components $\left(\mathrm{mJ} / \mathrm{m}^{2}\right)$} & $\begin{array}{c}\text { Total surface } \\
\text { energy, } \gamma\left(\mathrm{mJ} / \mathrm{m}^{2}\right)\end{array}$ & $\begin{array}{c}\text { Specific surface } \\
\text { area, } \gamma\left(\mathrm{m}^{2} / \mathrm{g}\right)\end{array}$ \\
\cline { 2 - 5 } & $\gamma^{\mathrm{LW}}$ & $\gamma^{+}$ & $\gamma^{-}$ & 199.2 & 0.382 \\
\hline Granite & 69.0 & 17.4 & 569.7 & 104.2 & 0.717 \\
\hline Limestone & 65.8 & 1.0 & 375.7 & & \\
\hline
\end{tabular}


Table 8: Bond energy ratios, ER1, ER2, ER3, ER4 for binder-aggregate combinations

\begin{tabular}{|c|c|c|c|c|}
\hline Material & ER & ER $_{2}$ & ER $_{3}$ & ER4 $^{|c|}$ Granite \\
\hline \multicolumn{5}{|c|}{} \\
\hline $40-60$ Neat & 0.88 & 0.59 & 0.33 & 0.22 \\
\hline $50 \%$ G & 1.12 & 0.74 & 0.43 & 0.28 \\
\hline $40 \%$ G+10\% HL & 1.35 & 0.88 & 0.52 & 0.33 \\
\hline $30 \%$ G+20\% HL & 3.61 & 2.71 & 1.38 & 1.03 \\
\hline \multicolumn{5}{|c|}{ Limestone } \\
\hline $40-60$ Neat & 1.29 & 0.80 & 0.92 & 0.57 \\
\hline $50 \%$ LS & 2.34 & 1.14 & 1.68 & 0.82 \\
\hline $40 \%$ LS+10\% HL & 2.72 & 1.38 & 1.95 & 0.99 \\
\hline $30 \%$ LS+20\% HL & 2.22 & 1.02 & 1.59 & 0.73 \\
\hline
\end{tabular}

